\title{
Improving Cost-effectiveness and Access to Cognitive Behavior Therapy for Depression: Providing Remote-Ready, Computer-Assisted Psychotherapy in Times of Crisis and Beyond
}

\author{
Michael E. Thase ${ }^{a, b}$ Paul McCrone ${ }^{c}$ Marna S. Barrett ${ }^{a}$ Tracy D. Eells ${ }^{d}$ \\ Stephen R. Wisniewski ${ }^{\mathrm{e}}$ G.K. Balasubramani ${ }^{\mathrm{e}}$ Gregory K. Brown ${ }^{\mathrm{a}, \mathrm{b}}$ \\ Jesse H. Wright ${ }^{d}$ \\ a Perelman School of Medicine, University of Pennsylvania, Philadelphia, PA, USA; ${ }^{\circ}$ Corporal Michael J Crescenz \\ Veterans Affairs Medical Center, Philadelphia, PA, USA; 'King's College, London, UK; ' Unversity of Louisville, \\ Louisville, KY, USA; ${ }^{\mathrm{e}}$ Graduate School of Public Health, University of Pittsburgh, Pittsburgh, PA, USA
}

\section{Keywords}

Computer-assisted cognitive behavior therapy · Depression · Cost-effectiveness

\begin{abstract}
Introduction: There is growing evidence that computer-delivered or computer-assisted forms of cognitive behavior therapy (CCBT) are helpful, but cost-effectiveness versus standard therapies is not well established. Objective: To evaluate the cost-effectiveness of a therapist-supported method for CCBT in comparison to standard cognitive behavior therapy (CBT). Methods: A total of 154 drug-free major depressive disorder outpatients were randomly assigned to either 16 weeks of standard CBT (up to twenty 50 -min sessions) or CCBT using the Good Days Ahead program (including up to $5.5 \mathrm{~h}$ of therapist contact). Outcomes were assessed at baseline, weeks 8 and 16, and at 3 and 6 months posttreatment. Economic analyses took into account the costs of services received and work/social role impairment. Results: In the context of almost identical efficacy, a form of CCBT that used only about one third the amount of therapist contact as conventional CBT was highly cost-effective compared
\end{abstract}

(c) 2020 S. Karger AG, Basel

www.karger.com/pp

Karger $\stackrel{2}{=}$ to conventional therapy and reduced the adjusted cost of treatment by USD 945 per patient. Conclusions: A method of CCBT that blended internet-delivered modules and abbreviated therapeutic contact reduced the cost of treatment substantially without adversely affecting outcomes. Results suggest that use of this approach can more than double the access to CBT. Because clinician support in CCBT can be provided by telephone, videoconference, and/or email, this highly efficient form of treatment could be a major advance in remote treatment delivery.

(c) 2020 S. Karger AG, Basel

\section{Introduction}

Cognitive behavior therapy (CBT) is the best-studied form of psychotherapy and is considered to be a first-line option for depressed outpatients in contemporary practice guidelines $[1,2]$. The efficacy of CBT in randomized controlled trials (RCTs) is comparable to that of antidepressant medications [3-5] and, when effective, the benefits may be more long-lasting than pharmacotherapy $[6$, 7]. Nevertheless, the public health impact of CBT is lim- 
ited by factors such as cost, the perceived inconvenience of traveling to weekly face-to-face sessions, and a shortage of trained therapists, particularly in public mental health settings or rural regions [8-10]. Computer-assisted models of CBT (CCBT) have been introduced over the past 25 years to reduce such barriers $[11,12]$. Several models of CCBT are accessible via the internet, thus facilitating remote treatment delivery [13-15]. The efficacy of CCBT is documented by meta-analyses of RCTs [16-18]. However, in studies that test CCBT as a "stand alone" intervention (i.e., no clinical support is provided), the observed effects are typically smaller than observed when CCBT includes at least several hours of therapist support [18, 19]. One approach to CCBT specifically developed for use as an adjunct to individual therapy, Good Days Ahead (GDA) [15], blends a 9-module multimedia program with abbreviated sessions with a clinician. Research conducted to date suggests that GDA has efficacy comparable to conventional CBT despite a substantial reduction in therapist contact $[20,21]$. The current report examines the costeffectiveness of GDA in the second, larger-scale RCT [21].

\section{Methods}

A detailed description of this two-center study is published elsewhere [21]. To summarize, the study was open to adult outpatients presenting for treatment of major depressive disorder (Structured Clinical Interview for DSM-IV) [22]. After completion of baseline evaluations, eligible, unmedicated patients scoring $\geq 14$ on the Hamilton Rating Scale for Depression (HAMD) [23] were randomized to receive either CCBT or CBT for 16 weeks of acutephase therapy. Experienced therapists $(n=9)$ conducted both interventions; mode-specific consultation was provided by two of the investigators (G.K. Brown and J.H. Wright) and centered on review of audio recordings to ensure protocol adherence.

The face-to-face component of CCBT consisted of a 50-min introductory session and eleven 25-min sessions. The first 9 sessions focused on one of the 9 internet-delivered GDA modules. The GDA software was accessible on PCs, laptops, or tablets; it was not fully operational on smartphones. Workstations with PCs were available for patients who did not have own their own devices. Patients were encouraged to work through each module at their own pace; generally, it took between 30 and 60 min to finish each module. After completion of the 9 modules, the final three 25 -min "booster" sessions focused on mastery of skills and practice of relapse prevention strategies. CCBT thus consisted of a maximum of $5.5 \mathrm{~h}$ of therapist contact.

Conventional CBT utilized the methods of Beck et al. [24], as updated by Beck [25] and Wright et al. [26]. To ensure a strong test of the efficacy of GDA, we employed a relatively intensive CBT protocol consisting of twenty 50 -min sessions (twice weekly for 4 weeks, weekly for 12 weeks; maximum therapist time: 16 h $40 \mathrm{~min}$ ) [27, 28]. Outcome assessments were conducted after 8 and 16 weeks of acutephase therapy and repeated at 3 and 6 months post-treatment.
Cost-effectiveness analyses were guided by the earlier reports of McCrone et al. [29, 30]. The Client Service Receipt Inventory (CSRI) [31], which was administered at baseline, week 16, and 3 and 6 months post-treatment, was used to record information on primary care and hospital-based services, as well as other community-based services and medications. The specific costs of CCBT were relatively small (total: USD 100 per patient, including the manufacturer's suggested license fee and hardware maintenance). Otherwise, the difference in cost of CBT and CCBT was largely determined by the study's design, as the CCBT group incurred only about one third of the cost attributable to therapist time of the CBT group. The costs of other services were based on local Medicaid, Medicare, and private insurer prices in addition to overheads for clinical space. Lost income was estimated using the human capital approach by combining lost workdays with average daily hourly earnings [31]. For the purposes of the cost-effectiveness evaluation, the Quality of Well Being Scale - Self Administered (QWBSA) [32] was used to generate quality-adjusted life years (QALYs), which permitted comparison of the results of the interventions evaluated here with other clinical interventions. Service costs and total costs (including lost workdays) were compared between the treatment groups using regression models, controlling for baseline differences. Bootstrap methods were used to produce confidence intervals around the cost differences due to the likely skewness in the distribution of regression residuals. The cost-effectiveness of CCBT and CBT was compared by combining service cost data and information on symptoms and QALYs [33]. If either intervention had both lower costs and better outcomes than the other, it would be the preferred option. Uncertainty in cost-effectiveness estimates was explored by calculating cost and outcome differences on 1,000 bootstrapped re-samples and plotting these on a cost-effectiveness plane. This analysis showed the probability that, when compared to CBT, CCBT could result in (i) lower costs and worse outcomes, (ii) higher costs and worse outcomes, (iii) lower costs and better outcomes, or (iv) higher costs and better outcomes. Cost-effectiveness acceptability curves were used to indicate the probability that CCBT or CBT was the most cost-effective option for different values placed on a unit improvement in outcome, i.e., one extra QALY.

\section{Results}

As reported elsewhere in detail [21], there were 154 patients in the intent-to-treat sample ( $n=77$ per group). The mean age of participants was 45 years, two thirds were female, three quarters were white, and about $50 \%$ had attended at least some years of college; there were no significant between-group differences at baseline. Acutephase completion rates were $79.2 \%$ for CBT $(16.0$ [SD = 5.0] sessions; $13.3 \mathrm{~h}$ of therapist contact) and $81.8 \%$ for CCBT $(8.1[\mathrm{SD}=2.1]$ GDA modules; 11.0 [SD $=3.0]$ therapy sessions; $5.0 \mathrm{~h}$ of therapist contact). CCBT met $a$ priori criteria for noninferiority to CBT. In the intent-totreat sample, for example, the CBT group had a mean HAMD score of $9.2(\mathrm{SD}=6.3$; 95\% CI: 7.6-10.8) at week 
Table 1. Use of services at baseline and 6-month follow-up

\begin{tabular}{|c|c|c|c|c|c|c|c|c|}
\hline Cognitive behavior therapy & $0(0)$ & $0(0)$ & $58(100)$ & $57(100)$ & - & - & $17.2(2.8)$ & $11.7(1.1)$ \\
\hline Primary care physician & $39(51)$ & $42(55)$ & $28(48)$ & $27(47)$ & $1.6(0.8)$ & $2.5(3.8)$ & $1.5(0.6)$ & $1.2(0.4)$ \\
\hline Emergency room & $11(14)$ & $13(17)$ & $6(10)$ & $9(16)$ & $1.0(0.0)$ & $1.1(0.3)$ & $1.2(0.4)$ & $1.1(0.3)$ \\
\hline Practice nurse & $9(12)$ & $11(14)$ & $4(7)$ & $2(4)$ & $1.3(0.7)$ & $1.2(0.4)$ & $1.3(0.5)$ & $2.0(1.4)$ \\
\hline District nurse & $2(3)$ & $0(0)$ & $0(0)$ & $0(0)$ & $1.5(0.7)$ & - & - & - \\
\hline Other nurse & $2(3)$ & $1(1)$ & $1(2)$ & $0(0)$ & $1.5(0.7)$ & $1.0(-)$ & $20.0(-)$ & - \\
\hline Health visitor & $0(0)$ & $0(0)$ & $1(2)$ & $1(2)$ & - & - & $20.0(-)$ & $6.0(-)$ \\
\hline Psychologist & $7(9)$ & $5(7)$ & $4(7)$ & $2(4)$ & $10.8(18.3)$ & $7.8(10.0)$ & $4.7(1.2)$ & $2.0(-)$ \\
\hline Social worker & $4(5)$ & $5(7)$ & $2(3)$ & $1(2)$ & $2.8(1.7)$ & $6.2(7.9)$ & $2.5(2.1)$ & $1.0(-)$ \\
\hline Homecare worker & $0(0)$ & $0(0)$ & $1(2)$ & $1(2)$ & - & - & $20.0(-)$ & $4.0(-)$ \\
\hline Housework & $0(0)$ & $0(0)$ & $0(0)$ & $0(0)$ & - & - & - & - \\
\hline Volunteer & $3(4)$ & $6(8)$ & $1(2)$ & $2(4)$ & $1.3(0.6)$ & $3.5(4.2)$ & $2.0(-)$ & $24.5(33.2)$ \\
\hline Inpatient (days) & $2(3)$ & $2(3)$ & $4(7)$ & $4(7)$ & $2.3(0.4)$ & $0.8(0.4)$ & $6.8(9.5)$ & $3.5(2.5)$ \\
\hline
\end{tabular}

16 or endpoint, whereas the CCBT group had a mean HAMD score of 8.9 ( $\mathrm{SD}=5.6$; 95\% CI: 7.5-10.3). Remission rates also were almost identical (CBT: $41.6 \%$; CCBT: $42.9 \%)$. Improvements were sustained at the 3 - and 6-month post-treatment follow-ups; fewer than $10 \%$ of remitters relapsed.

Service use and cost data in the 6 months prior to intake are summarized in Tables 1 and 2. Although total service use costs were slightly higher for the CCBT group, the difference was not significant because of substantial variability. About half of each group saw their primary care providers; most of the other services were seldom. At follow-up, these findings were largely unchanged, and therapy assignment did not affect subsequent service utilization (see Table 1). The total cost of care was significantly higher for CBT (USD 2,166) than CCBT (USD 1,247 ) (mean difference adjusted for baseline: USD 945; 95\% CI: USD 200-1,925; see Table 2). Mean QALYs over the follow-up were almost identical (CBT: 0.3412; CCBT: 0.3415). Adjusting for baseline quality of life and site resulted in 0.0007 more QALYs for CCBT ( $95 \%$ CI: -0.0141 to 0.0164 ). The cost-effectiveness plane demonstrated a 99.7\% likelihood that CCBT resulted in lower cost than CBT (see Fig. 1). Within the two quadrants representing simulations in which CCBT was significantly less costly, outcomes were almost evenly distributed: there was a $53.7 \%$ likelihood that CCBT resulted in greater QALYs than CBT and a $45.8 \%$ likelihood of fewer QALYs than CBT (see Fig. 1). At a threshold of USD 50,000 per QALY, there was a $96 \%$ likelihood that CCBT was the more costeffective option.

\section{Discussion}

Several methods of CCBT have been introduced to improve access to this effective form of psychotherapy of depression. Collectively, these therapies promise to reduce cost, enhance the convenience of treatment, allow for fully remote delivery, and maximize the impact of a limited number of trained therapists [34]. In parallel with these clinical developments, there has been substantial growth in research on CCBT for depression. One recent meta-analysis identified 40 RCTs from a wide range of countries [35]. Because all forms of CCBT use less therapeutic support than conventional psychotherapy, it is has been assumed that CCBT is a cost-effective strategy [10, $19,34,35]$. However, only a small number of earlier studies included the components necessary to assess cost-effectiveness in comparison to standard, first-line interven- 
Table 2. Mean (SD) service costs at baseline and follow-up (2013 USD)

\begin{tabular}{llllll}
\hline & \multicolumn{2}{l}{ Baseline } & & \multicolumn{2}{l}{ 6-Month follow-up } \\
\cline { 2 - 3 } \cline { 5 - 6 } Service & CBT & CCBT & & CBT & CCBT \\
\hline Cognitive behavior therapy & $0(0)$ & $0(0)$ & & $1,232(203)$ & $555(39)$ \\
Primary care physician & $105(125)$ & $175(394)$ & & $94(114)$ & $73(85)$ \\
Psychiatrist & $41(123)$ & $30(130)$ & & $20(76)$ & $23(90)$ \\
Other doctor & $267(590)$ & $430(1111)$ & & $114(167)$ & $170(316)$ \\
Emergency room & $102(252)$ & $130(301)$ & & $86(270)$ & $125(306)$ \\
Nurse & $23(57)$ & $18(44)$ & & $76(512)$ & $17(87)$ \\
Psychologist & $62(360)$ & $40(223)$ & & $25(95)$ & $9(50)$ \\
Counsellor & $42(171)$ & $38(132)$ & & $14(60)$ & $3(23)$ \\
Other therapist & $20(118)$ & $28(103)$ & & $44(260)$ & $21(155)$ \\
Alternative medicine & $63(231)$ & $45(202)$ & & $36(180)$ & $8(45)$ \\
Occupational therapist & $24(132)$ & $0(0)$ & $2(13)$ & $0(0)$ \\
Social worker & $4(18)$ & $5(20)$ & $3(15)$ & $3(15)$ \\
Homecare worker & $0(0)$ & $0(0)$ & $28(215)$ & $6(43)$ \\
Volunteer & $1(3)$ & $2(14)$ & & $<1(1)$ & $26(196)$ \\
Inpatient & $49(307)$ & $16(107)$ & $\mathbf{3 9 4}(2356)$ & $208(908)$ \\
\hline Total cost, USD & $\mathbf{7 7 8 ( 9 5 8 )}$ & $\mathbf{9 5 7 ( 1 , 3 3 2 )}$ & $\mathbf{2 , 1 6 4 ( 3 , 4 6 5 )}$ & $\mathbf{1 , 2 4 7}(\mathbf{1 , 4 2 3})^{\mathrm{a}}$ \\
\hline
\end{tabular}

a Adjusting for baseline costs, the mean difference at follow-up was USD 945 favoring CCBT (bootstrapped 95\% CI: USD 202-2,123).

Fig. 1. Cost-effectiveness plane comparing

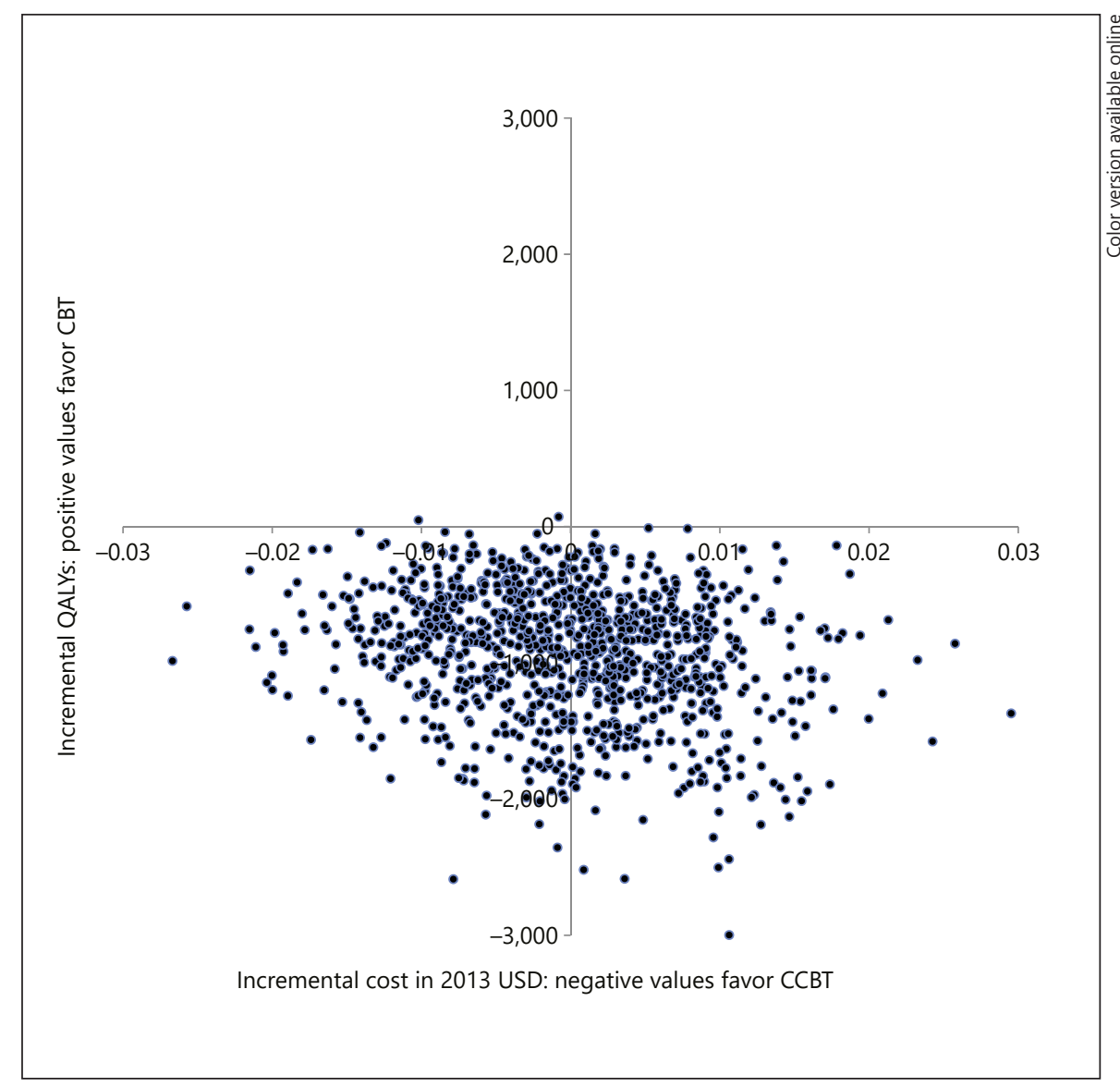
cremental costs. 
tions (i.e., randomization to a credible, active comparison group and a detailed assessment of service utilization, costs, and lost economic potential) [36-41]. Keeping in mind these limitations, results of a meta-analysis of the earlier RCTs suggested that CCBT may be more cost-effective than standard CBT [42].

The findings of the current report provide the strongest evidence of cost-effectiveness of CCBT to date. Not only did we find that the clinical benefits of a 16-week course of treatment with the GDA model of CCBT were noninferior to those of a relatively intensive course of individual CBT [21], such therapeutic equivalence was achieved with a cost savings of USD 945 per patient. One practical implication of the reduced use of therapist time is that nearly three times as many depressed people could be treated without any loss of clinical benefit if this approach was routinely used instead of conventional CBT as a first-line therapy.

The current study has several limitations [21]. Our therapists were highly experienced with conventional CBT and most learned to use GDA in order to participate in this study. As such, it is not known if less experienced or more eclectically oriented therapists could achieve comparable results. Conversely, it is possible that nondoctoral therapists or counselors could be trained to deliver CCBT, which could result in an even greater increase in cost-effectiveness.

A second limitation is that the "dose" of therapist time - up to $5.5 \mathrm{~h}$ across 16 weeks - is larger than used in most other investigations of CCBT. Because results of several meta-analyses suggest that as little as $1-3 \mathrm{~h}$ of therapist support may be sufficient to facilitate CCBT in some settings $[18,19,35]$, the cost-effectiveness of GDA could be further increased by a judicious reduction in therapist time. The importance of therapist support for treatment in clinical populations should not be minimized, however, as one large primary care study [43] that offered only a small amount (less than $10 \mathrm{~min}$ on average) of technical support found no clinical advantage compared to usual care.

At a time in which remote or "at home" access to therapy is urgently needed [34], a third limitation of our study is that therapeutic support was provided face-to-face. The web-based platform of the current edition of GDA is well suited to a range of remote applications and, since completing this study, our groups have gained extensive experience using telephone and videoconferencing. In our experience, both of these forms of support are judged to be useful by therapists and highly acceptable by depressed patients [44]. Other investigators have reported successful use of email or chat room support for delivery of CCBT [35]. Although videoconferencing has not yet been researched extensively, we predict that this method will be at least as effective as providing therapeutic support by telephone - a method with established efficacy for CBT [45-47].

Although the emphasis of this component of our research was on the cost-effectiveness of CCBT for depression, the impact of the COVID-19 pandemic underscores the potential public health significance of broader dissemination of modes of therapy for both depressive and anxiety disorders that do not require the patient and therapist to be in the same room [34]. Both voluntary quarantines and mandated social distancing policies preclude all forms of conventional psychotherapy at the very time that our anxious and depressed patients' worries and isolation may warrant even greater therapeutic support. In this regard, the availability of a range of programs that reliably deliver proven therapies at low cost has potentially great public health significance. Given the rapid progress in information technology and the growing sophistication of web-based therapeutic applications, there is good reason for optimism that even more efficient, accessible, and affordable therapies will be increasingly available to address common psychiatric conditions.

\section{Acknowledgments}

The authors wish to express their appreciation to the therapists for this study (Louisville: Don Kris Small, PhD, Virginia Evans, LCSW, Mary Hosey, LCSW, and Thomas Heddon, LCSW; Philadelphia: Elizabeth Hembree, PhD, Kevin Kuehlwein, PsyD, J. Russell Ramsay, PhD, and Rita Ryan, $\mathrm{PhD}$ ). At the Philadelphia site, one of the authors (M.E.T.) treated 2 patients during a staff shortage. We thank Kitty de Voogd, Jordan Coella, Christine Johnson, and Carol Wahl for their assistance. Andrew S. Wright, MD, and Aaron T. Beck, MD, coauthored the prototype for the GDA program along with one of the researchers (J.H.W.). Eve Phillips, MBA, provided support for the GDA software.

\section{Statement of Ethics}

All participants provided written informed consent for research participation. The Institutional Review Boards of our respective university medical centers approved the consent documents and the study was conducted according to the principles of ethical research practice outlined by the Declaration of Helsinki.

\section{Disclosure Statement}

Dr. Thase reports the following other relationships during the past 3 years. He has been an advisory/consultant to Acadia, Akili Inc., Alkermes, Allergan (Activis, Naurex), BioHaven, Boerhinger- 
Ingleheim, Calla Pharmaceuticals, Clexio Pharmaceuticals, GenoMind, Johnson \& Johnson (Janssen, Ortho-McNeil), Lundbeck, Otsuka, Pfizer, Sunovion, and Takeda. He received grant support from the Agency for Healthcare Research and Quality, Alkermes, Allergan (Forest Pharmaceuticals), Assurex, Axsome, BioHaven, Intracellular Therapeutics, Johnson \& Johnson (Janssen), Otsuka Pharmaceuticals, and Takeda. Dr. Thase received royalties from the American Psychiatric Press, Guilford Publications, Herald House, and W.W. Norton \& Company, Inc. Dr. Thase's spouse, Dr. Diane Sloan, works for Peloton Advantage, which does business with a number of pharmaceutical companies. None of the other authors at the Penn and University of Pittsburgh sites report disclosures or conflict of interest. Neither the Penn authors nor the University of Pennsylvania have any financial relationship with Empower Interactive or Mindstreet.
Dr. Jesse Wright is an author of Good Days Ahead (GDA) and has an equity interest in Empower Interactive and Mindstreet, developers and distributors of GDA. He receives no royalties or other payments from sales of this program. His conflict of interest is managed by an agreement with the University of Louisville. All other authors have no disclosures or conflict of interest regarding $G D A$ and no other disclosures pertaining to this research.

\section{Funding Sources}

This research was supported by grants R01-MH082762 (to J.H.W.) and R01-MH082794 (to M.E.T.) from the National Institute of Mental Health.

\section{References}

1 American Psychiatric Association. Practice guideline for the treatment of patients with major depressive disorder. 3rd ed [accessed 2016 Nov 27]. Arlington, VA. Available from: http://www.guideline.gov/content. aspx?id=24158.

2 Parikh SV, Quilty LC, Ravitz P, Rosenbluth M, Pavlova B, Grigoriadis S, et al.; CANMAT Depression Work Group. Canadian Network for Mood and Anxiety Treatments (CANMAT) 2016 clinical guidelines for the management of adults with major depressive disorder. Section 2. Psychological treatments. Can J Psychiatry. 2016 Sep;61(9):524-39.

3 Cuijpers P, Berking M, Andersson G, Quigley L, Kleiboer A, Dobson KS. A meta-analysis of cognitive-behavioural therapy for adult depression, alone and in comparison with other treatments. Can J Psychiatry. 2013 Jul;58(7): 376-85.

4 Cuijpers , van Straten A, van Oppen P, Andersson G. Are psychological and pharmacologic interventions equally effective in the treatment of adult depressive disorders? A meta-analysis of comparative studies. J Clin Psychiatry. 2008 Nov;69(11):1675-85.

5 Weitz ES, Hollon SD, Twisk J, van Straten A, Huibers MJ, David D, et al. Baseline depression severity as moderator of depression outcomes between cognitive behavioral therapy vs. pharmacotherapy: an individual patient data meta-analysis. JAMA Psychiatry. 2015 Nov;72(11):1102-9.

6 Vittengl JR, Clark LA, Dunn TW, Jarrett RB. Reducing relapse and recurrence in unipolar depression: a comparative meta-analysis of cognitive-behavioral therapy's effects. J Consult Clin Psychol. 2007 Jun;75(3):475-88.

7 Biesheuvel-Leliefeld KE, Kok GD, Bockting CL, Cuijpers P, Hollon SD, van Marwijk $\mathrm{HW}$, et al. Effectiveness of psychological interventions in preventing recurrence of depressive disorder: meta-analysis and metaregression. J Affect Disord. 2015 Mar; 174: 400-10.
8 Marcus SC, Olfson M. National trends in the treatment for depression from 1998 to 2007. Arch Gen Psychiatry. 2010 Dec;67(12):126573.

9 Blane D, Williams C, Morrison J, Wilson A, Mercer S. Cognitive behavioural therapy: why primary care should have it all. Br J Gen Pract. 2013 Feb;63(607):103-4.

10 Eells TD, Barrett MS, Wright JH, Thase M. Computer-assisted cognitive-behavior therapy for depression. Psychotherapy (Chic). 2014 Jun;51(2):191-7.

11 Greist JH. Computer interviews for depression management. J Clin Psychiatry. 1998;59 Suppl 16:20-4.

12 Wright $\mathrm{JH}$, Wright AS. Computer-assisted psychotherapy. J Psychother Pract Res. 1997; 6(4):315-29.

13 Beating the Blues US - Helping you to manage your emotional well-being [accessed 2016 Nov 27]. Available from: http://beatingthebluesus.com/.

14 MoodGYM training program [accessed 2016 Nov 27]. Available from: https://moodgym. anu.edu.au/welcome.

15 Empower Interactive. Good Days Ahead [accessed 2016 Nov 27]. Available from: http:// www.empower-interactive.com/solutions/ good-days-ahead/.

16 Richards D, Richardson T. Computerbased psychological treatments for depression: a systematic review and meta-analysis. Clin Psychol Rev. 2012 Jun;32(4):32942.

17 Arnberg FK, Linton SJ, Hultcrantz M, Heintz E, Jonsson U. Internet-delivered psychological treatments for mood and anxiety disorders: a systematic review of their efficacy, safety, and cost-effectiveness. PLoS One. 2014 May;9(5):e98118.

18 So M, Yamaguchi S, Hashimoto S, Sado M, Furukawa TA, McCrone P. Is computerised CBT really helpful for adult depression? A meta-analytic re-evaluation of CCBT for adult depression in terms of clinical imple- mentation and methodological validity. $\mathrm{BMC}$ Psychiatry. 2013 Apr;13(1):113.

19 Andersson G, Topooco N, Havik O, Nordgreen T. Internet-supported versus face-toface cognitive behavior therapy for depression. Expert Rev Neurother. 2016;16(1):5560.

20 Wright JH, Wright AS, Albano AM, Basco MR, Goldsmith LJ, Raffield T, et al. Computer-assisted cognitive therapy for depression: maintaining efficacy while reducing therapist time. Am J Psychiatry. 2005 Jun;162(6):115864 .

21 Thase ME, Wright JH, Eells TD, Barrett MS, Wisniewski SR, Balasubramani GK, et al. Improving the efficiency of psychotherapy for depression: computer-assisted versus standard CBT. Am J Psychiatry. 2018 Mar;175(3): 242-50.

22 First MB, Spitzer RL, Gibbon M, Williams JW. Structured Clinical Interview for DSM-5 Axis I Disorders. Research version, patient/ non-patient edition (SCID-I/P w/PSY SCREEN). New York: Biometrics Research, New York State Psychiatric Institute; 2015.

23 Hamilton M. A rating scale for depression. J Neurol Neurosurg Psychiatry. 1960 Feb; 23(1):56-62.

24 Beck AT, Rush AJ, Shaw BF, et al. Cognitive therapy of depression. New York: Guilford; 1979.

25 Beck J. Cognitive therapy: basics and beyond. vol 2. New York: Guilford; 2011.

26 Wright JH, Brown GK, Thase ME, Basco MR. Learning cognitive-behavior therapy: an illustrated guide. 2nd ed. Arlington (VA): American Psychiatric Publishing, Inc.; 2017.

27 Thase ME, Simons AD, Cahalane J, McGeary J, Harden T. Severity of depression and response to cognitive behavior therapy. Am J Psychiatry. 1991 Jun;148(6):784-9.

28 Thase ME, Reynolds CF 3rd, Frank E, et al. Response to cognitive behavior therapy in chronic depression. J Psychother Pract Res. 1994;3:204-14. 
29 McCrone P, Knapp M, Proudfoot J, Ryden C, Cavanagh K, Shapiro DA, et al. Cost-effectiveness of computerised cognitive-behavioural therapy for anxiety and depression in primary care: randomised controlled trial. $\mathrm{Br}$ I Psychiatry. 2004 Jul;185(1):55-62.

30 McCrone P, Sharpe M, Chalder T, Knapp M, Johnson AL, Goldsmith KA, et al. Adaptive pacing, cognitive behaviour therapy, graded exercise, and specialist medical care for chronic fatigue syndrome: a cost-effectiveness analysis. PLoS One. 2012; 7(8):e40808.

31 Beecham J, Knapp M. Costing psychiatric interventions. In: Thornicroft G, Brewin CR, Wing J, editors. Measuring mental health needs. London: Gaskell/Royal College of Psychiatrists; 2001. pp. 163-83.

32 Pyne JM, Sieber WJ, David K, Kaplan RM, Hyman Rapaport M, Keith Williams D. Use of the quality of well-being self-administered version (QWB-SA) in assessing health-related quality of life in depressed patients. J Affect Disord. 2003 Sep;76(1-3):237-47.

33 Thompson SG, Barber JA. How should cost data in pragmatic randomised trials be analysed? BMJ. 2000 Apr;320(7243):1197-200.

34 Wright JH, Caudill R. Remote treatment delivery in response to the COVID-19 pandemic. Psychother Psychosom. 2020 Mar, Epub ahead of print.

35 Wright JH, Owen JJ, Richards D, Eells TD, Richardson T, Brown GK, et al. Computerassisted cognitive-behavior therapy for depression: a systematic review and meta-analysis. J Clin Psychiatry. 2019 Mar;80(2): $18 \mathrm{r} 12188$
36 Gerhards SA, de Graaf LE, Jacobs LE, Severens JL, Huibers MJ, Arntz A, et al. Economic evaluation of online computerised cognitivebehavioural therapy without support for depression in primary care: randomised trial. $\mathrm{Br}$ J Psychiatry. 2010 Apr;196(4):310-8.

37 Hollinghurst S, Peters TJ, Kaur S, Wiles N, Lewis G, Kessler D. Cost-effectiveness of therapist-delivered online cognitive-behavioural therapy for depression: randomised controlled trial. Br J Psychiatry. 2010 Oct; 197(4): 297-304.

38 Titov N, Dear BF, Ali S, Zou JB, Lorian CN, Johnston L, et al. Clinical and cost-effectiveness of therapist-guided internet-delivered cognitive behavior therapy for older adults with symptoms of depression: a randomized controlled trial. Behav Ther. 2015 Mar;46(2): 193-205.

39 Warmerdam L, Smit F, van Straten A, Riper $\mathrm{H}$, Cuijpers P. Cost-utility and cost-effectiveness of internet-based treatment for adults with depressive symptoms: randomized trial. J Med Internet Res. 2010 Dec;12(5):e53.

40 Solomon D, Proudfoot J, Clarke J, Christensen H. e-CBT (myCompass), antidepressant medication, and face-to-face psychological treatment for depression in Australia: a cost-effectiveness comparison. J Med Internet Res. 2015 Nov;17(11):e255.

41 Holst A, Björkelund C, Metsini A, Madsen JH, Hange D, Petersson EL, et al. Cost-effectiveness analysis of internet-mediated cognitive behavioural therapy for depression in the primary care setting: results based on a controlled trial. BMJ Open. 2018 Jun;8(6):e019716.
42 Kolovos S, van Dongen JM, Riper H, Buntrock C, Cuijpers P, Ebert DD, et al. Cost effectiveness of guided Internet-based interventions for depression in comparison with control conditions: an individual-participant data meta-analysis. Depress Anxiety. 2018 Mar;35(3):209-19.

43 Duarte A, Walker S, Littlewood E, Brabyn S, Hewitt C, Gilbody S, et al. Cost-effectiveness of computerized cognitive-behavioural therapy for the treatment of depression in primary care: findings from the Randomised Evaluation of the Effectiveness and Acceptability of Computerised Therapy (REEACT) trial. Psychol Med. 2017 Jul;47(10):1825-35.

44 Antle BF, Owen JJ, Eells TD, Wells MJ, Harris LM, Cappiccie A, et al. Dissemination of computer-assisted cognitive-behavior therapy for depression in primary care. Contemp Clin Trials. 2019 Mar;78:46-52.

45 Mohr DC, Hart SL, Julian L, Catledge C, Honos-Webb L, Vella L, et al. Telephone-administered psychotherapy for depression. Arch Gen Psychiatry. 2005 Sep;62(9):1007-14.

46 Mohr DC, Ho J, Duffecy J, Reifler D, Sokol L, Burns MN, et al. Effect of telephone-administered vs face-to-face cognitive behavioral therapy on adherence to therapy and depression outcomes among primary care patients: a randomized trial. JAMA. 2012 Jun;307(21): 2278-85.

47 Mohr DC, Lattie EG, Tomasino KN, Kwasny MJ, Kaiser SM, Gray EL, et al. A randomized noninferiority trial evaluating remotely-delivered stepped care for depression using internet cognitive behavioral therapy (CBT) and telephone CBT. Behav Res Ther. 2019 Dec;123:103485. 